\title{
Label- and amplification-free electrochemical detection of bacterial ribosomal RNA
}

\author{
Grace Henihan $^{a}$, Holger Schulze $e^{a}$, Damion K. Corrigan ${ }^{a, b}$, Gerard Giraud $^{c}$, Jonathan G. \\ Terry $^{e}$, Alison Hardie ${ }^{f}$, Colin J. Campbell ${ }^{b}$, Anthony J. Walton ${ }^{e}$, Jason Crain $^{c, d}$, Ronald Pethig $^{e}$, \\ Kate E. Templeton ${ }^{a, f}$, Andrew R. Mount ${ }^{b}$, Till T. Bachmann ${ }^{a}$
}
${ }^{a}$ Division of Infection and Pathway Medicine, College of Medicine and Veterinary Medicine, The University of Edinburgh, Chancellor's Building, 49 Little France Crescent, Edinburgh EH16 4SB, Scotland, UK
${ }^{b}$ School of Chemistry, The University of Edinburgh, Joseph Black Building, The King's Buildings, West Mains Road, Edinburgh, EH9 3JJ, Scotland, UK

${ }^{c}$ School of Physics and Astronomy, The University of Edinburgh, The King's Buildings, West Mains Road, Edinburgh, EH9 3JZ, Scotland, UK

\footnotetext{
${ }^{d}$ National Physical Laboratory, Hampton Road, Teddington, Middlesex TW11 OLW, UK

${ }^{e}$ Institute for Integrated Micro and Nano Systems, School of Engineering, The University of Edinburgh, Alexander Crum Brown Road, Edinburgh EH9 3FF, Scotland, UK

${ }^{f}$ Department of Laboratory Medicine, Royal Infirmary of Edinburgh, Edinburgh EH16 4SA, Scotland, UK
}

Corresponding author: phone: +44 131242 9438, fax: +44 131242 6244; email: Till.Bachmann@ed.ac.uk

* These authors contributed equally to this study 


\begin{abstract}
Current approaches to molecular diagnostics rely heavily on PCR amplification and optical detection methods which have restrictions when applied to point of care (POC) applications. Herein we describe the development of a label-free and amplification-free method of pathogen detection applied to $E$. coli which overcomes the bottleneck of complex sample preparation and has the potential to be implemented as a rapid, cost effective test suitable for point of care use. Ribosomal RNA is naturally amplified in bacterial cells, which makes it a promising target for sensitive detection without the necessity for prior in vitro amplification.

Using fluorescent microarray methods with rRNA targets from a range of pathogens, an optimal probe was selected from a pool of probe candidates identified in silico. The specificity of probes was investigated on DNA microarray using fluorescently labelled 16S rRNA target. The probe yielding highest specificity performance was evaluated in terms of sensitivity and a LOD of 20 pM was achieved on fluorescent glass microarray. This probe was transferred to an EIS end point format and specificity which correlated to microarray data was demonstrated. Excellent sensitivity was facilitated by the use of uncharged PNA probes and large 16S rRNA target and investigations resulted in an LOD of $50 \mathrm{pM}$. An alternative kinetic EIS assay format was demonstrated with which rRNA could be detected in a species specific manner within 10-40 min at room temperature without wash steps.
\end{abstract}

\title{
Keywords
}

Molecular diagnostics, electrochemical impedance spectroscopy, 16S ribosomal RNA, E. coli, pathogen detection, PCR-free 


\section{Introduction}

Infectious diseases have a major impact on public health causing approximately 15 million deaths each year which represents $26 \%$ of the annual mortality worldwide (Fauci and Morens 2012; Morens and Fauci 2012). Molecular diagnostics plays an integral part in diminishing the impact of infectious diseases on public health. In particular point of care diagnostics for infectious disease have potential to improve clinical care outcomes by optimising prescribing decisions, and improving efficiency of care (Howick et al. 2014). Nucleic acid target amplification techniques such as polymerase chain reaction (PCR) and isothermal amplification methods like e.g. loop-mediated isothermal amplification (LAMP), helicase-dependent amplification (HDA), and rolling circle amplification (RCA) have gained a substantial role in clinical applications (Emmadi et al. 2011;Franca et al. 2013;Muldrew 2009). Although PCR and real-time PCR achieve excellent limit of detections (LOD), the instrumental and operational requirements paired with the time-to-result (TTR) for these techniques are often prohibitive for point-of-care (POC) applications (Gubala et al. 2012).

Electrochemical biosensors have favorable attributes for POC applications, such as capacity to be low cost, compact, portable, and have the potential for label-free target detection (Wang 2006). But until now, reports of methods which avoid target amplification prior to hybridization followed by electrochemical detection have been rare. The research group of Shana O. Kelley used signal amplification based on $\mathrm{Ru}^{3+}$ adsorption towards hybridized target nucleic acids and $\mathrm{Fe}^{3+}$ amplification at the surface of nanostructured microelectrodes for the direct detection of $E$. coli mRNA by differential pulse voltammetry and combined this with electrochemical lysis of bacterial cells (Besant et al. 2013;Sage et al. 2014). Several groups applied enzymatic signal amplification using Streptavidin-conjugated horseradish peroxidase or alkaline phosphatase 
bound to the hybridized 16S rRNA via biotinylated detection probes or biotinylated intercalator for the amperometric detection of bacterial RNA (Elsholz et al. 2006;Gau et al. 2001;Liao et al. 2006; Liao et al. 2007; Sin et al. 2013;Williams et al. 2003;Zimdars et al. 2015). All these enzymatic signal amplification methods require multiple incubation and washing steps which makes them less amenable to implementation in a fully integrated sample-to-answer system.

Electrochemical impedance spectroscopy is a powerful tool to generate point-of-care tests (POCT) as it is a label-free detection technology enabling the direct detection of targets binding to immobilized probes without the requirement of any kind of target labelling or further binding of detection probes. This makes EIS an ideal detection method to be integrated into truly portable sample-to-answer POCT. EIS has demonstrated multiparametric detection capability enabling the label-free detection of nucleic acids, whole cells, small molecules and proteins on the same platform as shown previously by ourselves (Ciani et al. 2012; Corrigan et al. 2013; Corrigan et al. 2012; Huang et al. 2015) and other groups as described in reviews (Gebala and Schuhmann 2012;Katz and Willner 2003;Paenke et al. 2008;Park Jin -Young and Park Su-Moon 2009). This great potential for EIS-based biosensors is reflected in an increasing number of publications in recent years. Most of these publications however lack evidence for potential real-world application in clinical POC settings, as investigations are executed with short synthetic targets rather than clinical samples. Faradaic impedance spectroscopy is performed in the presence of redox species in the bulk solution which is alternatively oxidized and reduced. EIS detection of nucleic acid targets is usually performed in the presence of negatively charged redox species in the measurement buffer e.g. potassium hexacyanoferrate (Kafka et al. 2008). The accumulation of negative charges during the hybridization process of the target DNA towards DNA probes 
immobilized on electrode surfaces causes a repulsion of the redox species, thus inhibiting the redox reaction and enhancing the charge transfer resistance value. In order to enhance the signal difference before and after hybridization of the nucleic acid target to the immobilized probe layer, uncharged peptide nucleic acid (PNA) probes have been applied instead of DNA probes (Corrigan et al. 2012;Degefa and Kwak 2008;Keighley et al. 2008a;Liu et al. 2005). Several EIS studies with immobilized DNA and PNA probes have been performed so far with short artificial targets or PCR products (Corrigan et al. 2014;Corrigan et al. 2012;Degefa \& Kwak 2008; Ghindilis et al. 2009;Huang et al. 2015;Kafka et al. 2008;Keighley et al. 2008a;Keighley et al. 2008b;Riedel et al. 2014). We have shown recently the target amplification-free detection of MRSA genomic DNA (Corrigan et al. 2013) and amplification-free detection of bacterial plasmid DNA (Huang et al. 2015). Park et al. detected HCV RNA by EIS using PNA probes (Park et al. 2010).

Here we report to the best of our knowledge the first example of a direct label- and amplification free EIS-based detection of bacterial 16S ribosomal RNA for bacterial species identification. Our approach takes advantage of rRNA large target size and of its naturally high number of copies present in bacteria. 


\section{Experimental Section}

\section{Bacterial culture and RNA isolation}

S. aureus, $P$. aeruginosa and E. coli clinical isolates from the Edinburgh Royal Infirmary were subcultured onto Columbia blood agar and incubated overnight at $37^{\circ} \mathrm{C}$ in a $\mathrm{CO}_{2}$ incubator. The bacterial cells were harvested during mid-logarithmic growth, when RNA levels are at their highest due to high metabolic activity. Cells were inoculated into saline solution and the optical density measured using a Densicheck (bioMerieux). This gives values in McFarland units, proportional to the cellular concentration of bacteria in the suspension. E. coli DH10 $\beta$ liquid cultures were prepared by inoculating $2.5 \mathrm{~mL}$ Luria-Bertani (LB) medium (10 g/L Bactotryptone, $5 \mathrm{~g} / \mathrm{L}$ yeast extract, $10 \mathrm{~g} / \mathrm{L} \mathrm{NaCl}$ ) with an $E$. coli $\mathrm{DH} 10 \beta$ colony from a LB agar plate and incubated for $16 \mathrm{~h}$ at $37{ }^{\circ} \mathrm{C}$ in a shaking incubator. Protocols 4 and 7 from the RNAprotect Bacteria Reagent Handbook (Qiagen, $2^{\text {nd }}$ edition 2005) were followed with a few minor alterations. The RNA is stabilised, before lysis, by the addition of RNAprotect Bacteria Reagent (Qiagen). This prevents degradation of RNA transcripts and induction of genes. The bacterial suspension ( $1 \mathrm{ml})$ was added to $2 \mathrm{ml}$ of the stabilising reagent. After centrifugation and pelleting, the bacteria were disrupted by enzymatic lysis and Proteinase K digestion. Lysostaphin was used for Gram-positive bacteria such as $S$. aureus, while lysozyme was used for Gram-negatives. The manufacturer's recommended incubation time with these lytic enzymes has been increased from 10 to $30 \mathrm{~min}$, followed by $10 \mathrm{~min}$ incubation with Proteinase K. The incubation temperature has also been increased to $37^{\circ} \mathrm{C}$. The lysozyme, as per instructions, was used at $15 \mathrm{mg} / \mathrm{ml}$ of $\mathrm{TE}$ buffer. Lysostaphin was used at $50 \mu \mathrm{g} / \mathrm{ml}$. 
Total RNA was then purified from the bacterial lysate using the RNeasy Mini Kit (Qiagen). Remaining DNA has been removed by on-column DNase digestion with DNase 1. After purification, RNA was eluted from spin columns into two separate aliquots of $30 \mu \mathrm{L}$. Total RNA eluate was quantified spectrophotometrically (Nanodrop, from Labtech, Sussex, UK).

\section{Fluorescence labelling}

RNA was fluorescence labelled using Cy3 Label-IT Nucleic Acid kit (Mirus Bio, LLC) according to the manufacturer's instructions. This kit covalently binds Cy3 residues at a site other than that used in base pairing and suitable for hybridization experiments.

\section{PNA microarray fabrication}

Thiol-modified PNA oligonucleotides were spotted in 1x Schott Nexterion spot buffer $(20 \mu \mathrm{M})$ in replicates of three within each array on Schott Nexterion Slides E (epoxy silane modified surface; Schott, Jena, Germany) with four $200 \mu \mathrm{m}$ diameter split pins and a MicroGrid II (BioRobotics, Cambridge, UK) at 40-50\% relative humidity at room temperature. Epoxysilane slides were immediately immobilized at a relative humidity of $75 \%$ at room temperature for 1 hour followed by storage over night at room temperature under dry conditions. This generated spots with a diameter of approximately $200 \mu \mathrm{m}$. The slides were then washed with $0.1 \%$ TritonX-100 solution under constant mixing for $5 \mathrm{~min}$ at $\mathrm{RT}$, with $1 \mathrm{mM} \mathrm{HCl}$ solution for $4 \mathrm{~min}$, with $100 \mathrm{mM} \mathrm{KCl}$ solution for $10 \mathrm{~min}$, and with deionized water for $1 \mathrm{~min}$. The slides were blocked with $50 \mathrm{mM}$ ethanolamine $+0.1 \%$ sodium dodecyl sulphate (SDS) in $0.1 \mathrm{M}$ Tris buffer (pH 9) for $15 \mathrm{~min}$ at $50{ }^{\circ} \mathrm{C}$. After blocking the slides were washed in deionized water for $1 \mathrm{~min}$ and then dried by centrifugation ( $2 \mathrm{~min}$ at $800 \mathrm{~g}$ ). 


\section{Microarray hybridization and data acquisition}

Microarray hybridization was performed using Agilent 8 gasket slides (Agilent Technologies, Stockport, UK) and hybridization chambers with the printed slide which had been washed and blocked placed array facing downward, in contact with the hybridization solution. All rRNA hybridizations were performed in $50 \mu \mathrm{L}$ hybridization solution $(2 \mathrm{x}$ SSPE buffer $+0.01 \%$ SDS + $100 \mathrm{nM}$ hybridization control) at $55^{\circ} \mathrm{C}$ for 2 hours under rotation in a pre-heated Agilent hybridization oven. Following incubation, slides were washed with 2x SSC + 0.1\% SDS for 10 min, 2x SSC for $10 \mathrm{~min}, 0.2 \mathrm{x}$ SSC for $10 \mathrm{~min}$. Each slide was then dipped in $\mathrm{H}_{2} \mathrm{O}$ for a few seconds and dried by centrifugation for $2 \mathrm{~min}$ at $800 \mathrm{~g}$.

Fluorescence images were generated with a Tecan LS Reloaded fluorescence scanner (Tecan, Maennedorf, Switzerland) with excitation at $532 \mathrm{~nm}$ and emission at $575 \mathrm{~nm}$. Quantification of fluorescence signal intensities was performed with the Quantarray software (Perkin Elmer, Waltham, MA) using the Histogram quantification method. For further analysis, the mean signal intensity minus local background intensity was processed with Excel (Microsoft Corp., Redmond, USA) and the mean and standard deviation of all replicates were calculated.

\section{Electrode Cleaning and Functionalization}

Screen printed dual gold working electrode $(1.75 \mathrm{~mm} \times 4 \mathrm{~mm})$ sensors with an integrated $\mathrm{Ag} / \mathrm{AgCl}$ reference electrode and a gold counter electrode (Dropsens, Oviedo, Spain) used for

kinetic EIS testing were cleaned using cyclic voltammetry in $100 \mathrm{mM}$ aqueous sulphuric acid solution applying ten $\mathrm{CV}$ cycles between $0-1.6 \mathrm{~V}$ and three cycles between $0-1.3 \mathrm{~V}$ as described 
in previous publication from this laboratory (Corrigan et al. 2012). For end point EIS assays, gold disc electrodes (2 $\mathrm{mm}$ diameter) purchased from IJ Cambria Scientific (Carms, UK) were mechanically polished using alumina powder, rinsed and cleaned for $10 \mathrm{~min}$ with piranha solution (6 mL concentrated $\mathrm{H}_{2} \mathrm{SO}_{4}+2 \mathrm{~mL} 30 \%$ (v/v) $\mathrm{H}_{2} \mathrm{O}_{2}$ solution; caution: such solution should be handled with extreme care) as described previously by our group (Corrigan et al. 2012).

After cleaning, all electrodes were incubated with a solution of $1.5 \mu \mathrm{M}$ thiol-modified PNA solution $+30 \mu \mathrm{M}$ mercaptohexanol $+5 \mathrm{mM}$ Tris(2-carboxyethyl)phosphine in 50\% (v/v) DMSO for $16 \mathrm{~h}$ at room temperature for Dropsens electrodes and $30^{\circ} \mathrm{C}$ for IJ Cambria gold disc electrodes, respectively. Electrodes were rinsed in 50\% (v/v) DMSO and incubated in $1 \mathrm{mM}$ mercaptohexanol $+5 \mathrm{mM}$ Tris(2-carboxyethyl)phosphine in $50 \%(\mathrm{v} / \mathrm{v})$ DMSO for $1 \mathrm{~h}$ at $30{ }^{\circ} \mathrm{C}$. Then gold disc electrodes were washed with 50\% (v/v) DMSO and the EIS measurement buffer $\left(0.1 \mathrm{mM} \mathrm{K}_{3}\left[\mathrm{Fe}(\mathrm{CN})_{6}\right]+0.1 \mathrm{mM} \mathrm{K} \mathrm{K}_{4}\left[\mathrm{Fe}(\mathrm{CN})_{6}\right]+10 \mathrm{mM}\right.$ phosphate buffer $)$ for $2 \mathrm{~h}$ and $1 \mathrm{~h}$, respectively. Screen printed dual gold working electrode were washed with $50 \%$ (v/v) DMSO and the EIS measurement buffer $\left(0.1 \mathrm{mM} \mathrm{K}_{3}\left[\mathrm{Fe}(\mathrm{CN})_{6}\right]+0.1 \mathrm{mM} \mathrm{K} \mathrm{K}_{4}\left[\mathrm{Fe}(\mathrm{CN})_{6}\right]+10 \mathrm{mM}\right.$ phosphate buffer $+20 \mathrm{mM} \mathrm{NaCl}$ ) for $1 \mathrm{~h}$ and $5 \mathrm{~min}$, respectively.

\section{EIS measurements}

End point EIS measurements were performed using a three electrode system with an $\mathrm{Ag} / \mathrm{AgCl}$ $(3 \mathrm{M} \mathrm{KCl})$ reference electrode and a platinum wire counter electrode (both from Metrohm, Herisau, Switzerland) connected to an Autolab potentiostat PGSTAT12 running FRA software (Metrohm, Herisau, Switzerland). EIS measurements were performed at a DC potential of 0.19 V 
with an amplitude of $10 \mathrm{mV}$ rms using a frequency range between $100,000 \mathrm{~Hz}$ and $0.1 \mathrm{~Hz}(15$ frequencies) in $0.1 \mathrm{mM} \mathrm{K}_{3}\left[\mathrm{Fe}(\mathrm{CN})_{6}\right]+0.1 \mathrm{mM} \mathrm{K}_{4}\left[\mathrm{Fe}(\mathrm{CN})_{6}\right]+10 \mathrm{mM}$ phosphate buffer, pH 7.0 $+20 \mathrm{mM} \mathrm{NaCl}$. Hybridization took place using $50 \mu \mathrm{L}$ of $16 \mathrm{~S}$ rRNA solution in $2 \times \mathrm{SSC}$ for $2 \mathrm{~h}$ at $55^{\circ} \mathrm{C}$. After hybridization electrodes were washed with $2 \times \mathrm{SSC}, 0.2 \times \mathrm{SSC}$ and EIS measurement buffer for $10 \mathrm{~min}$ in each. Data were collected in the form of Nyquist plots and fitted to the wellestablished Randles Equivalent Circuit (Randles 1947). Values for Rct had errors typically of 5 10\% and this agreed with previous studies (Corrigan et al. 2013).

Kinetic EIS measurements were performed on screen printed sensors connected to an Autolab potentiostat at open circuit potential at an amplitude of $10 \mathrm{mV} \mathrm{rms}$ at 15 frequencies in the range $100000 \mathrm{~Hz}-0.1 \mathrm{~Hz}$. Hybridization and measurement were performed in measurement buffer consisting of $0.1 \mathrm{mM} \mathrm{K}_{4}\left[\mathrm{Fe}(\mathrm{CN})_{6}\right]+0.1 \mathrm{mM} \mathrm{K}_{3}\left[\mathrm{Fe}(\mathrm{CN})_{6}\right]+10 \mathrm{mM}$ phosphate buffer $\mathrm{pH} 7.0+$ $20 \mathrm{mM} \mathrm{NaCl}$. Ribosomal RNA sample solutions were heated to $95^{\circ} \mathrm{C}$ for $5 \mathrm{~min}$, and transferred to ice for 2 min prior to measurement. A baseline measurement was preformed target free in measurement buffer. Following one EIS spectrum on each electrode the solution was replaced with measurement buffer containing target rRNA. 


\section{Results and Discussion}

\section{Fluorescence microarray-based probe evaluation}

In this paper we report the development of an EIS-based procedure for direct label- and amplification-free detection of rRNA for bacterial species identification based on immobilized species specific probes. By employing fluorescent microarray methods, an optimal probe was identified which allowed sensitive and specific $E$. coli rRNA detection when transferred to the EIS platform, as schematically depicted in Figure 1. The experimental microarray probe evaluation was necessary because the hybridization efficiency of certain probes depends on the relative probe/ target position and the accessibility of the target, which differs significantly between different types of targets (e.g. PCR products and rRNA). As a large number of published probe sequences for bacterial species identification are available, we selected a panel of such probes for screening. The specificity of the probes was tested against the ARB ribosomal RNA database created by Wolfgang Ludwig et al (Ludwig et al. 2004) from the Technical University of Munich, using the probeCheck online tool from the Department of Microbial Ecology from the University of Vienna (http://131.130.66.200/cgibin/probecheck/probecheck.pl) (Loy et al. 2007). Probe sequences selected were predominantly targeted against $16 \mathrm{~S}$ ribosomal RNA. Some of the published probes, especially several E. coli probes from Francois et al. did not show the expected specificity for E. coli in silico and were therefore removed from the panel (Francois et al. 2006). Four previously published E. coli specific probes were tested in-silico and immobilized as PNA variants on glass microarrays with fluorescence-labeled rRNA, as can be seen in Figure 2. The sequence of probes P51 and P52 were deduced from published $E$. coli specific DNA probes based on a literature survey of 
published species specific probes targeting the 16S rRNA (Anzai et al. 2008; Behrens et al. 2003a;Elsholz et al. 2006;Francois et al. 2006;Jin et al. 2008;Wiesinger-Mayr et al. 2007). Probes P92 and P93 were previously used by Stender et al. and Perry-O'Keefe et al. as PNA probes in in-situ hybridization assays (Perry-O'Keefe et al. 2001;Stender et al. 2001). The four different PNA probes were tested against fluorescence-labeled rRNA from $E$. coli, $P$. aeruginosa, and S. aureus in order to investigate the hybridization efficiency and specificity of the selected probes. As can be seen in Figure 2, the four E. coli specific probes varied in their behavior in terms of hybridization yield and specificity. Probes P93 and P51 showed the highest fluorescence intensities when hybridized with E. coli rRNA, however probe P92 showed the lowest degree of cross-hybridization with $P$. aeruginosa, and $S$. aureus rRNA, respectively. Variation in specificity and fluorescence yield of interactions between probes taken from the literature and the target of interest highlights the importance of experimental investigation of sequences using a method such as DNA microarray following in silico checks. The different degrees of cross-hybridization can be explained by the sequence homology of the probes with the P. aeruginosa, and $S$. aureus rRNA sequence. Regions of the probe which share complementarity with that of other pathogens as well as the target itself are difficult to avoid. This is particularly true for highly conserved $16 \mathrm{~S}$ rRNA sequences, however due to the endogenous amplification of rRNA, with approximately 20,000 rRNA copies per E. coli cell (Zwirglmaier et al. 2004), it is nonetheless a desirable target. Investing focus on selection and experimental validation of probe sequences, as tested herein, allows specificity challenges to be overcome, such that the advantage of endogenous high copy number on detection sensitivity can be exploited. In this case probe P93 has nine adjacent nucleotides complementary towards $P$. aeruginosa and three nucleotides complementary to $S$. aureus rRNA according to the sequence 
alignment data shown by Stender et al (Stender et al. 2001). Probe 92 only has five adjacent nucleotides complementary towards $P$. aeruginosa, and four adjacent nucleotides complementary towards $S$. aureus rRNA. The low specificity of probe 51 can be explained by a region of ten nucleotides within the probe sequence which is complementary towards the $P$. aeruginosa, and $S$. aureus rRNA sequence. Based on this microarray results probe P92 was selected for further tests.

\section{Insert Figure 1 here}

Hybridization of E. coli rRNA to probe 92 on the fluorescence glass microarray platform was performed over a concentration range of $0.02 \mathrm{nM}-2 \mathrm{nM}$ to determine the limit of detection (LOD) (see Figure 2). The LOD defined by the mean signal of the buffer control plus three time the standard deviation was determined to be $20 \mathrm{pM}$. This is in the range of LODs typically obtained when short artificial targets are hybridized to DNA microarrays. In a previous study we obtained LODs of $10 \mathrm{pM}$ with amino-modified probes specific for human cytomegalovirus (HCMV) and hepatitis C virus (HCV) immobilized on epoxy silane functionalized glass microarray slides when hybridized to short artificial targets (Schulze et al. 2011). This relatively low LOD of probe P92 towards full length E. coli $16 \mathrm{~S}$ rRNA indicates a good accessibility of the probe sequence on the target. The secondary structure of the rRNA causes clear differences in the accessibility of different regions of the 16S rRNA as shown by Behrens et al (Behrens et al. 2003a;Behrens et al. 2003b).

Insert Figure 2 here 


\section{Electrochemical impedance spectroscopy end-point measurements}

The E. coli specific PNA probe P92 was selected for testing by EIS. P92 was immobilized as PNA probe on gold electrodes for label-and amplification-free detection of 16S rRNA (see Figure 1). Figure 3 (left) shows the Nyquist plots obtained on electrodes functionalized with P92

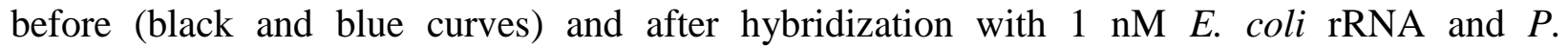
aeruginosa rRNA, respectively. Figure 3 (right) shows the mean signal increase ratios obtained after hybridization with $0.05 \mathrm{nM}$ and $1 \mathrm{nM}$ target and non-target rRNA. The specificity obtained in the end-point EIS measurement correlated well with the specificity obtained in the fluorescence-based microarray experiments (see Figure 3). Hybridization with $1 \mathrm{nM}$ E. coli rRNA caused a more than $700 \%$ increase relative to the baseline electron charge transfer resistance (Rct) value. This shows the high sensitivity of the system, which we think is attributed to the use of an uncharged PNA probe layer and to the fact that a large target molecule with a high number of negative charges binds to this uncharged probe layer in combination with the negatively charged electroactive species in solution (Ferri-/Ferrocyanide) causing a larger Rct increase. This dependency of the signal change on the target size can also be seen in Figure 4. Hybridization with $1 \mathrm{nM}$ full length $16 \mathrm{~S}$ rRNA (appr. $1.5 \mathrm{~kb}$ ) caused an 8.4 times signal increase, whereas the same concentration of a complementary 20mer artificial target caused no detectable signal increase. These results are in agreement with EIS data which we obtained recently with New Delhi Metallo-beta-lactamase (NDM) gene specific PNA probes tested either with 620 nucleotide long single-stranded PCR products and 20 nucleotide long artificial targets,

respectively. Tests performed with the longer PCR products yielded a 100-times lower LOD of $100 \mathrm{pM}$ compared to the short 20mer target $(\mathrm{LOD}=10 \mathrm{nM})($ Huang et al. 2015). 
We also investigated the impact of the hybridization condition $\left(2 \mathrm{~h}\right.$ at $\left.55{ }^{\circ} \mathrm{C}\right)$ on the rRNA integrity and demonstrate that both $16 \mathrm{~S}$ and $23 \mathrm{~S}$ rRNA peaks are present following EIS hybridization protocol. Figure S1 shows an Agilent 2100 Bioanalyzer electropherogram of an $E$. coli rRNA sample before (black curve) and after $2 \mathrm{~h}$ hybridization at $55^{\circ} \mathrm{C}$ (red), which indicates that we detect full length $16 \mathrm{~S}$ rRNA in the EIS assay and that the rRNA is not fragmented or degraded during the $2 \mathrm{~h}$ incubation at $55^{\circ} \mathrm{C}$.

\section{Insert Figure 3 here}

\section{Insert Figure 4 here}

The dose-response curve in Figure 5 shows the sensitivity and LOD of the EIS end-point measurement of $E$. coli rRNA. The LOD was determined to be $50 \mathrm{pM}$ and was therefore in the same range as that of the fluorescence-based microarray system. This achievement is significant as the EIS based system offers attributes amenable to POC diagnostic application like e.g. labelfree target detection and low cost portable instrumentation which are not achievable with the fluorescence-based benchmark microarray method used here for probe development only. As rRNA is present at approx. 20,000 copies per cell this theoretically equates to detection of bacteria in the attomolar range, or to detection of approx. 500 bacteria $(\mathrm{CFU}) / \mathrm{mL}$ (Rastogi 2006). Park et al. reported a LOD of 23 pM for the EIS-based detection of short artificial 15 mer RNA targets with immobilized PNA probes (Park et al. 2010). The authors applied a sophisticated but laborious mixed monolayer based on a self-synthesized crown either which binds ammonium modified PNA probes. Although the LOD reported by Park et al. is slightly 
lower than in this study, improved sensitivity of detection is achieved here, and greater discrimination of baseline and target hybridization is achieved. Park et al. observed a 2.2 times signal increase at $1 \mathrm{nM}$ target concentration compared to our 8.4 times signal increase (see Figure 5).

\section{Insert Figure 5 here}

\section{Electrochemical impedance spectroscopy kinetic measurements}

In addition to end-point measurements we also performed kinetic EIS measurements where change in Rct is monitored in real time during the hybridization process. In this case the target solution was present in the measurement buffer and EIS measurements were continuously repeated during the hybridization without change of solution and addition of washing steps after hybridization (see Figure 1). We have shown previously that this procedure can be used to detect MRSA specific PCR product hybridization (Corrigan et al. 2012). Figure 6 shows that we can also detect direct rRNA hybridization within $<10$ minutes at room temperature. This is an important step towards an on-site point-of-care test for bacterial species identification. These tests were performed with Dropsens screen-printed gold electrodes which contained two working electrodes together with a common gold counter and silver/silver chloride pseudo reference electrode on a single chip. On each chip one of the working electrodes was functionalized with a mixed monolayer of the E. coli specific PNA probe P92 together with mercaptohexanol, whereas the second working electrode was functionalized only with mercaptohexanol. The mercaptohexanol functionalized electrode served as a negative control showing the degree of unspecific binding of target molecules to the electrode surface. Following a baseline measurement preformed in target free measurement buffer, the solution was replaced by 
measurement buffer containing target rRNA and EIS measurements were continuously repeated. By monitoring the change in Rct over repeated EIS spectra, hybridization of rRNA to probe 92 was monitored with respect to time. Data in Figure 6 are normalized against the initial measurements of each electrode showing the signal increase ratio at different time points of the hybridization with $750 \mathrm{pM} \mathrm{E}$. coli and $P$. aeruginosa rRNA. A fractional Rct increase of greater than 100\% was detected on P92 functionalized electrode after hybridization with E. coli rRNA already within the first 10 min of incubation. This increase was much lower on electrodes which were hybridized with non-complementary $P$. aeruginosa rRNA, where a small increase in Rct was observed for the initial measurements followed by a nearly unchanged signal. This shows the high degree of specificity which was obtained under these non-stringent conditions, with hybridization at room temperature far below the melting temperature of the applied PNA probe, and the absence of any washing steps.

This makes the direct label-free rRNA detection an ideal candidate for POCT development for pathogen detection. Direct target detection, which does not require the use of an enzyme label for signal amplification as used in many amperometric pathogen biosensors significantly reduces the complexity of the test and simplifies the integration of the detection method into a microfluidic sample-to-answer cartridge with pre-loaded reagents. Nevertheless, amperometric biosensors, which use e.g. horseradish peroxidase or alkaline phosphatase enzyme labels for signal amplification are interesting alternatives for bacteria detection as they also enable direct PCRfree bacterial rRNA detection. Liao et al. and Elsholz et al. reported LODs of $4 \times 10^{4} \mathrm{CFU} / \mathrm{mL}$ and $10^{5} \mathrm{CFU} / \mathrm{mL}(0.5 \mathrm{ng} / \mu \mathrm{L}$ total RNA) which are slightly higher than the LOD obtained in this study (Elsholz et al. 2006;Liao et al. 2006). Zimdars et al recently reported a very low LOD of $30 \mathrm{fM} 16 \mathrm{~S}$ rRNA using a biotinylated intercalator as a coupling site for a streptavidin/alkaline 
phosphatase enzyme label (Zimdars et al. 2015). But these enzyme label based amperometric biosensors have several disadvantages regarding POCT development. Amperometric biosensors with enzyme labels such as horseradish peroxidase or alkaline phosphatase require the integration of substrate solutions and several washing steps. The long term stability of enzymes in a microfluidic cartridge can also pose a challenge and could potentially significantly increase the assay costs if low temperature storage and shipment of the microfluidic cartridge is required. Interesting alternatives to ribosomal RNA based pathogen detection methods are whole bacteria diagnostic tests which have the advantage that they do not require bacterial cell lysis and nucleic acid extraction and purification (Hassan et al. 2015; Morales-Narvaez et al. 2015). This makes the integration of such a test into a sample-to-answer system much easier. Especially, EIS-based methods with immobilized bacteria specific antibodies have been proven to enable direct labelfree detection of whole bacteria and were applied for the detection of various bacteria with a wide range of LODs reported, ranging from $2 \mathrm{CFU} / \mathrm{mL}$ to $10^{6} \mathrm{CFU} / \mathrm{mL}$ (Ahmed et al. 2014; dos Santos et al. 2013; Yang et al. 2004). A challenge of these immunodetection methods is the stability of the antibodies during and after immobilization. The shelf life of antibodies on the sensor surface is not very long and the binding efficiency tends to decrease over time (Ahmed et al. 2014). Whereas, the PNA probes used in the herein described method are very stable as they are resistant to nucleases and proteases, which should simplify the long term storage of electrodes with functionalized PNA probes and significantly enhance the shelf life of PNA functionalized electrodes compared to electrodes with immobilized antibodies. 


\section{Insert Figure 6 here}

\section{Further development}

The next step towards a fully integrated sample-to-answer system is the combination of the detection module with a sample preparation module including sampling, e.g. via nasal swabs and bacterial cell lysis. There are examples of successful integration of swab based sampling, enzymatic cell lysis and Boom method based nucleic acid purification in a microfluidic chip (Van Heirstraeten et al. 2014). Even so the work by van Heirstraeten et al. is an excellent example of the integration of lab processes into a microfluidic chip, the use of a large number of different solutions for lysis and purification including required buffer exchanges and a potential need for cold storage of the cartridge depending on the long term storage stability of the applied enzymes can make the final product quite expensive and difficult to produce. We are working on novel sample preparation approaches better adapted to fully integrated microfluidic POCT for infectious diseases and especially antibiotic resistance diagnostics.

\section{Conclusion}

We report the successful development of an EIS biosensor for direct detection of E. coli $16 \mathrm{~S}$ rRNA. Designed with implementation in point of care applications in mind, the biosensor is characterised by rapid, sensitive, specific rRNA detection with no requirement for sample amplification, labelling or fragmentation. The kinetic EIS assay format has the capacity for miniaturisation and microfluidic cartridge integration.

Oligonucleotide probe sequences for E. coli rRNA detection were identified in published literature and interrogated in silico. Probes were screened in vitro using fluorescence-based 
microarrays. Based on microarray specificity and sensitivity data, a probe was selected for implementation in EIS molecular diagnostic assay development. In the absence of specificity enhancement associated with target amplification, focus was invested in demonstrating the capacity for specific detection, while taking advantage of target rRNA high copy number.

Due to target size and accessibility considerations in EIS assay development, our approach of probe screening using in silico analysis, fluorescence-based microarray, followed by an endpoint EIS assay format has repeatedly allowed us to identify successful EIS probe candidates (Huang et al. 2015).

An EIS detection assay was developed with a LOD of $50 \mathrm{pM}$, comparable to that achieved by fluorescence-based microarray but with POC compatible characteristics. Furthermore a kinetic EIS assay format allowed specific detection of E. coli $16 \mathrm{~S}$ rRNA within $10 \mathrm{~min}$ at ambient temperature. 


\section{Acknowledgements}

This work was funded by ITI Techmedia/Scottish Enterprise under the Chronic Wound Care

(CWC) program. The authors would like to thank Ilenia Ciani and Peter Ghazal for being part of the CWC team and for fruitful discussions during the project. 


\section{Figure captions:}

Figure 1: A brief schematic of experimental process described herein. Following in silico probe selection, fluorescently labelled rRNA is applied to an in-house microarray populated with $E$. coli rRNA specific PNA probes (A), as a probe selection screen. For EIS assay development, probes found to be of highest sensitivity and specificity for target E. coli rRNA are applied in gold electrode functionalization (B). The gold electrode biosensor is incubated with intact unlabelled rRNA (C) under controlled conditions and stringency washes (D) are performed, followed by EIS measurement in a conventional three electrode system electrochemical cell (E). EIS measurement of functionalized electrode background $(\mathrm{H})$ and specific hybridization (I) is detected as change in charge transfer resistance (Rct). Our kinetic EIS setup (F, G) allows realtime detection of rRNA hybridization rapidly, using low cost screen printed electrodes without a requirement for washing. Specific rRNA hybridization $(G)$ causes repulsion of the redox species ferricyanide and change in charge transfer resistance (Rct) is proportional to the hybridized target concentration (I).

Figure 2: Left: Mean fluorescence intensities obtained at four different E. coli specific PNA probes (P51, P52, P92, P93) after hybridization with 1nM fluorescence-labeled E. coli, P. aeruginosa, and S. aureus rRNA, respectively. Right: Dose-response curve obtained with E. coli specific PNA probe P92 immobilized on glass microarray slides which were hybridized with different concentrations of fluorescence-labeled $E$. coli $16 \mathrm{~S}$ rRNA; $n=3$. An inset figure of fluorescence intensities obtained from rRNA concentrations between 0 - 500 pM can be found in the supporting information as Figure S-2. 
Figure 3: Left: Nyquist plot obtained with electrodes 1 and 2 with E. coli specific PNA probe P92 immobilised on both of them before (black and blue curve) and after 2 h hybridization with $1 \mathrm{nM}$ E. coli (red) and $P$. aeruginosa rRNA (green) rRNA, respectively. Right: Mean signal increase ratios obtained with $E$. coli specific PNA probe P92 after hybridization with E. coli (black) and $P$. aeruginosa rRNA (red) rRNA, respectively; $\mathrm{n}=3$.

Figure 4: Comparison of EIS signal increase ratios obtained with E. coli specific PNA probe P92 after hybridization with short 20mer artificial targets and full length E. coli 16S rRNA, respectively.

Figure 5: EIS dose-response curve obtained with E. coli specific PNA probe P92 immobilized on gold electrodes which were hybridized for $2 \mathrm{~h}$ at $55^{\circ} \mathrm{C}$ with different concentrations of unlabeled E. coli $\mathrm{rRNA} ; \mathrm{n}=3$. An inset figure of signal increase ratios obtained from rRNA concentrations from 0 - $100 \mathrm{pM}$ can be found in the supporting information as Figure S-3.

Figure 6: Signal increase ratios obtained at screen-printed electrodes functionalised with E. coli specific PNA probe P92 and MCH only (negative control), respectively, following exposure to $750 \mathrm{pM}$ E. coli and $P$. aeruginosa rRNA in EIS measurement buffer, respectively. EIS measurements were continuously repeated in the presence of the target solution without any washing steps. 


\section{References}

Ahmed, A., Rushworth, J.V., Hirst, N.A., \& Millner, P.A. 2014. Clinical Microbiology Reviews, 27, (3) 631-646.

Anzai, Y., Saito, S., Fujimoto, K., Konoshita, K., \& Kato, F. 2008. J.Health Sci., 54, (2) 229234.

Behrens, S., Fuchs, B.M., Mueller, F., \& Amann, R. 2003a. Appl.Environ.Microbiol., 69, (8) 4935-4941.

Behrens, S., Ruhland, C., Inacio, J., Huber, H., Fonseca, A., Spencer-Martins, I., Fuchs, B.M., \& Amann, R. 2003b. Appl.Environ.Microbiol., 69, (3) 1748-1758.

Besant, J.D., Das, J., Sargent, E.H., \& Kelley, S.O. 2013. ACS Nano, 7, (9) 8183-8189.

Ciani, I., Schulze, H., Corrigan, D.K., Henihan, G., Giraud, G., Terry, J.G., Walton, A.J., Pethig, R., Ghazal, P., Crain, J., Campbell, C.J., Bachmann, T.T., \& Mount, A.R. 2012. Biosensors \& Bioelectronics, 31, (1) 413-418.

Corrigan, D.K., Schulze, H., Henihan, G., Hardie, A., Ciani, I., Giraud, G., Terry, J.G., Walton, A.J., Pethig, R., Ghazal, P., Crain, J., Campbell, C.J., Templeton, K.E., Mount, A.R., \& Bachmann, T.T. 2013. Analyst, 138, (22) 6997-7005.

Corrigan, D.K., Schulze, H., McDermott, R.A., Schmuser, I., Henihan, G., Henry, J.B., Bachmann, T.T., \& Mount, A.R. 2014. Journal of Electroanalytical Chemistry, 732, 25-29.

Corrigan, D.K., Schulze, H., Henihan, G., Ciani, I., Giraud, G., Terry, J.G., Walton, A.J., Pethig, R., Ghazal, P., Crain, J., Campbell, C.J., Mount, A.R., \& Bachmann, T.T. 2012. Biosensors and Bioelectronics, 34, (1) 178-184.

Degefa, T.H. \& Kwak, J. 2008. Journal of Electroanalytical Chemistry, 612, (1) 37-41.

dos Santos, M.B., Agusil, J.P., Prieto-Simon, B., Sporer, C., Teixeira, V., \& Samitier, J. 2013. Biosensors \& Bioelectronics, 45, 174-180.

Elsholz, B., Worl, R., Blohm, L., Albers, J., Feucht, H., Grunwald, T., Jurgen, B., Schweder, T., \& Hintsche, R. 2006. Analytical Chemistry, 78, (14) 4794-4802.

Emmadi, R., Boonyaratanakomkit, J.B., Selvarangan, R., Shyamala, V., Zimmer, B.L., Williams, L., Bryant, B., Schutzbank, T., Schoonmaker, M.M., Wilson, J.A.A., Hall, L., Pancholi, P., \& Bernard, K. 2011. Journal of Molecular Diagnostics, 13, (6) 583-604. 
Fauci, A.S. \& Morens, D.M. 2012. New England Journal of Medicine, 366, (5) 454-461.

Franca, R.F.O., da Silva, C.C., \& De Paula, S.O. 2013. European Journal of Clinical Microbiology \& Infectious Diseases, 32, (6) 723-728.

Francois, P., Charbonnier, Y., Jacquet, J., Utinger, D., Bento, M., Lew, D., Kresbach, G.M., Ehrat, M., Schlegel, W., \& Schrenzel, J. 2006. Journal of Microbiological Methods, 65, (3) 390403.

Gau, J.J., Lan, E.H., Dunn, B., Ho, C.M., \& Woo, J.C.S. 2001. Biosensors \& Bioelectronics, 16, (9-12) 745-755.

Gebala, M. \& Schuhmann, W. 2012. Physical Chemistry Chemical Physics, 14, (43) 1493314942 .

Ghindilis, A.L., Smith, M.W., Schwarzkopf, K.R., Zhan, C.Q., Evans, D.R., Baptista, A.M., \& Simon, H.M. 2009. Electroanalysis, 12, (13) 1459-1468.

Gubala, V., Harris, L.F., Ricco, A.J., Tan, M.X., \& Williams, D.E. 2012. Analytical Chemistry, 84, (2) 487-515.

Hassan, A.R.H.A., Escosura-Muniz, A., \& Merkoci, A. 2015. Biosensors \& Bioelectronics, 67, 511-515.

Howick, J., Cals, J.W.L., Jones, C., Price, C.P., Pluddemann, A., Heneghan, C., Berger, M.Y., Buntinx, F., Hickner, J., Pace, W., Badrick, T., Van den Bruel, A., Laurence, C., van Weert, H.C., van Severen, E., Parrella, A., \& Thompson, M. 2014. Bmj Open, 4, (8).

Huang, J.M., Henihan, G., Macdonald, D., Michalowski, A., Templeton, K., Gibb, A.P., Schulze, H., \& Bachmann, T.T. 2015. Anal.Chem., 87, (15) 7738-7745.

Jin, D., Qi, H., Chen, S., Zeng, T., Liu, Q., \& Wang, S. 2008. J.Microbiol.Methods, 75, (2) 365368.

Kafka, J., Panke, O., Abendroth, B., \& Lisdat, F. 2008. Electrochimica Acta, 53, (25) 7467-7474.

Katz, E. \& Willner, I. 2003. Electroanalysis, 15, (11) 913-947.

Keighley, S.D., Estrela, P., Li, P., \& Mighorato, P. 2008a. Biosensors \& Bioelectronics, 24, (4) 906-911.

Keighley, S.D., Li, P., Estrela, P., \& Mighorato, P. 2008b. Biosensors \& Bioelectronics, 23, (8) 1291-1297.

Liao, J.C., Mastali, M., Gau, V., Suchard, M.A., Moller, A.K., Bruckner, D.A., Babbitt, J.T., Li, Y., Gornbein, J., Landaw, E.M., Mccabe, E.R.B., Churchill, B.M., \& Haake, D.A. 2006. Journal of Clinical Microbiology, 44, (2) 561-570. 
Liao, J.C., Mastali, M., Li, Y., Gau, V., Suchard, M.A., Babbitt, J., Gornbein, J., Landaw, E.M., Mccabe, E.R.B., Churchill, B.M., \& Haake, D.A. 2007. Journal of Molecular Diagnostics, 9, (2) $158-168$.

Liu, J.Y., Tian, S.J., Nielsen, P.E., \& Knoll, W. 2005. Chemical Communications (23) 29692971.

Loy, A., Maixner, F., Wagner, M., \& Horn, M. 2007. Nucleic Acids Research, 35, D800-D804.

Ludwig, W., Strunk, O., Westram, R., Richter, L., Meier, H., Yadhukumar, Buchner, A., Lai, T., Steppi, S., Jobb, G., Forster, W., Brettske, I., Gerber, S., Ginhart, A.W., Gross, O., Grumann, S., Hermann, S., Jost, R., Konig, A., Liss, T., Lussmann, R., May, M., Nonhoff, B., Reichel, B., Strehlow, R., Stamatakis, A., Stuckmann, N., Vilbig, A., Lenke, M., Ludwig, T., Bode, A., \& Schleifer, K.H. 2004. Nucleic Acids Research, 32, (4) 1363-1371.

Morales-Narvaez, E., Naghdi, T., Zor, E., \& Merkoci, A. 2015. Analytical Chemistry, 87, (16) 8573-8577.

Morens, D.M. \& Fauci, A.S. 2012. Mbio, 3, (6).

Muldrew, K.L. 2009. Current Opinion in Pediatrics, 21, (1) 102-111.

Paenke, O., Balkenhohl, T., Kafka, J., Schaefer, D., \& Lisdat, F. 2008. Biosensing for the 21St Century, 109, 195-237.

Park Jin -Young \& Park Su-Moon 2009. Sensors, 9, 9513-9532.

Park, J.Y., Lee, Y.S., Chang, B.Y., Kim, B.H., Jeon, S., \& Park, S.M. 2010. Analytical Chemistry, 82, (19) 8342-8348.

Perry-O'Keefe, H., Rigby, S., Oliveira, K., Sorensen, D., Slender, H., Coull, J., \& HyldigNielsen, J.J. 2001. Journal of Microbiological Methods, 47, (3) 281-292.

Randles, J.E.B. 1947. Discussions of the Faraday Society, 1, 11-19.

Rastogi, S.C. 2006. Cell And Molecular Biology New Age International (P) Limited.

Riedel, M., Kartchemnik, J., Schoning, M.J., \& Lisdat, F. 2014. Analytical Chemistry, 86, (15) 7867-7874.

Sage, A.T., Besant, J.D., Lam, B., Sargent, E.H., \& Kelley, S.O. 2014. Accounts of Chemical Research, 47, (8) 2417-2425.

Schulze, H., Ross, A.J., Ember, S.W.J., Luby, J., Khondoker, M., Giraud, G., Ciani, I., Tlili, C., Papale, D., Terry, J.G., Mount, A.R., Walton, A.J., Crain, J., Ghazal, P., Bachmann, T.T., \& Campbell, C.J. 2011. Faraday Discuss., 149, 201-210.

Sin, M.L.Y., Gau, V., Liao, J.C., \& Wong, P.K. 2013. Journal of Microelectromechanical Systems, 22, (5) 1126-1132. 
Stender, H., Broomer, A.J., Oliveira, K., Perry-O'Keefe, H., Hyldig-Nielsen, J.J., Sage, A., \& Coull, J. 2001. Applied and Environmental Microbiology, 67, (1) 142-147.

Van Heirstraeten, L., Spang, P., Schwind, C., Drese, K.S., Ritzi-Lehnert, M., Nieto, B., Camps, M., Landgraf, B., Guasch, F., Corbera, A.H., Samitier, J., Goossens, H., Malhotra-Kumar, S., \& Roeser, T. 2014. Lab on A Chip, 14, (9) 1519-1526.

Wang, J. 2006. Biosens.Bioelectron., 21, (10) 1887-1892.

Wiesinger-Mayr, H., Vierlinger, K., Pichler, R., Kriegner, A., Hirschl, A.M., Presterl, E., Bodrossy, L., \& Noehammer, C. 2007. BMC.Microbiol., 7, 78.

Williams, E., Pividori, M.I., Merkoci, A., Forster, R.J., \& Alegret, S. 2003. Biosensors \& Bioelectronics, 19, (3) 165-175.

Yang, L.J., Li, Y.B., \& Erf, G.F. 2004. Analytical Chemistry, 76, (4) 1107-1113.

Zimdars, A., Gebala, M., Hartwich, G., Neugebauer, S., \& Schuhmann, W. 2015. Talanta, 143, 19-26.

Zwirglmaier, K., Ludwig, W., \& Schleifer, K.H. 2004. Molecular Microbiology, 51, (1) 89-96. 


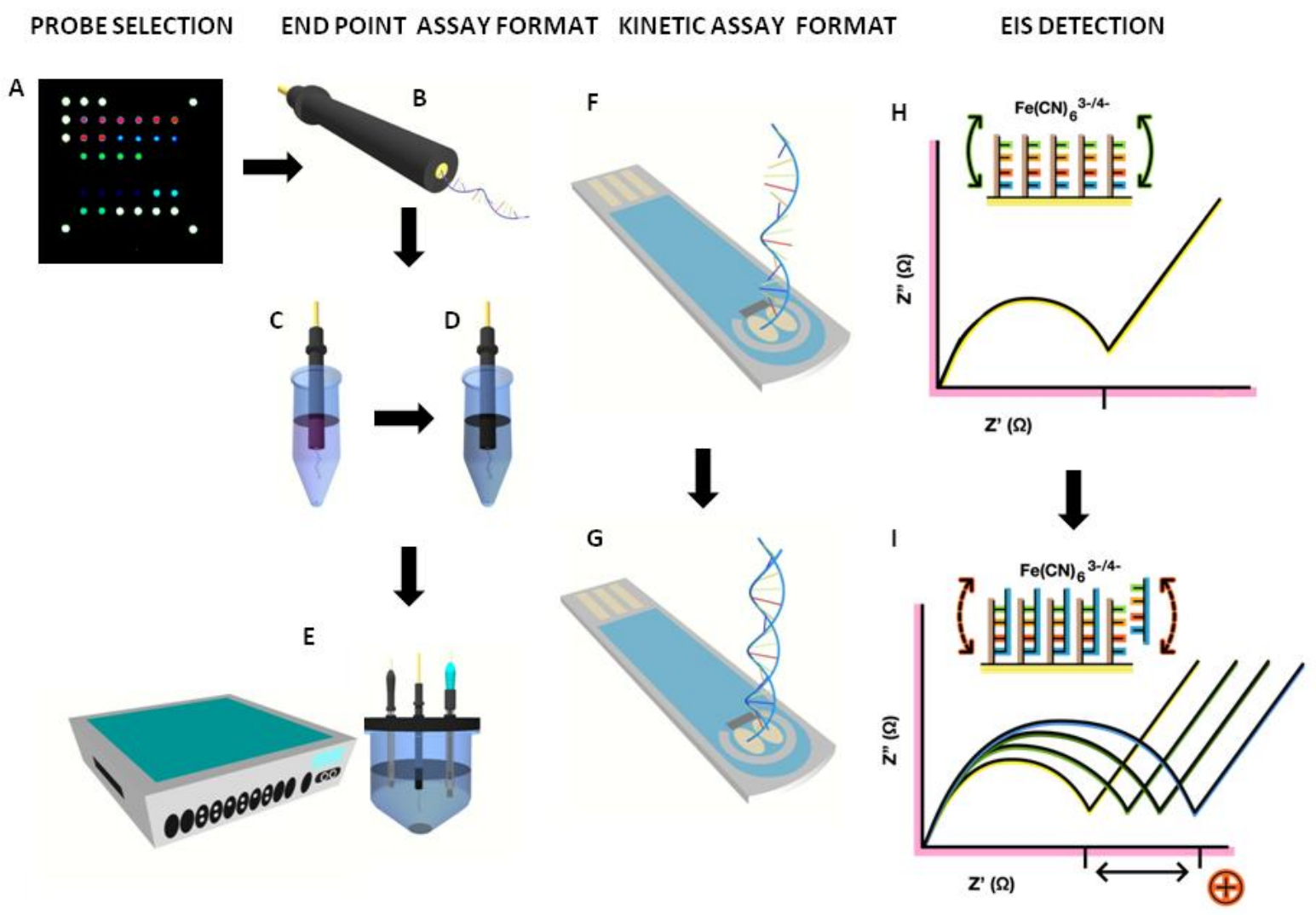

Figure 1 

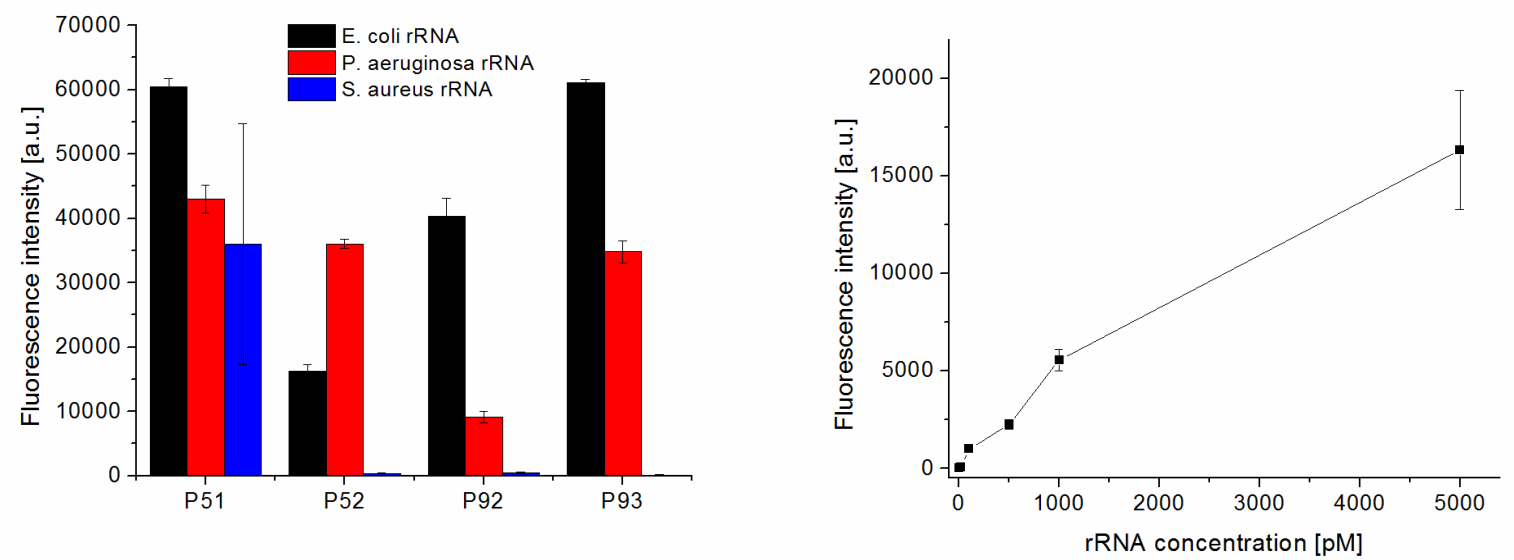

Figure 2 

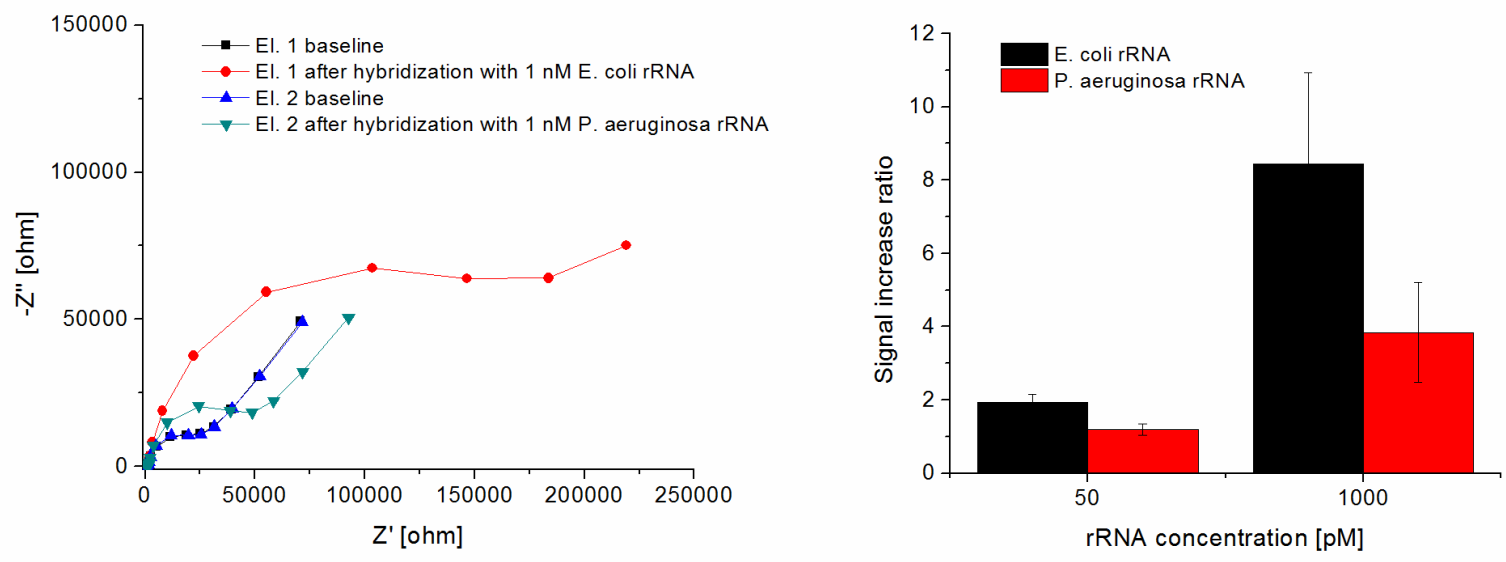

Figure 3 


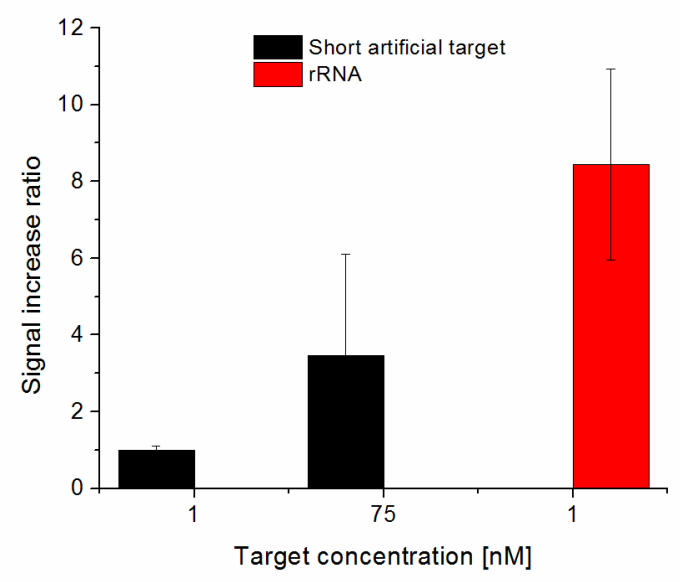

Figure 4 


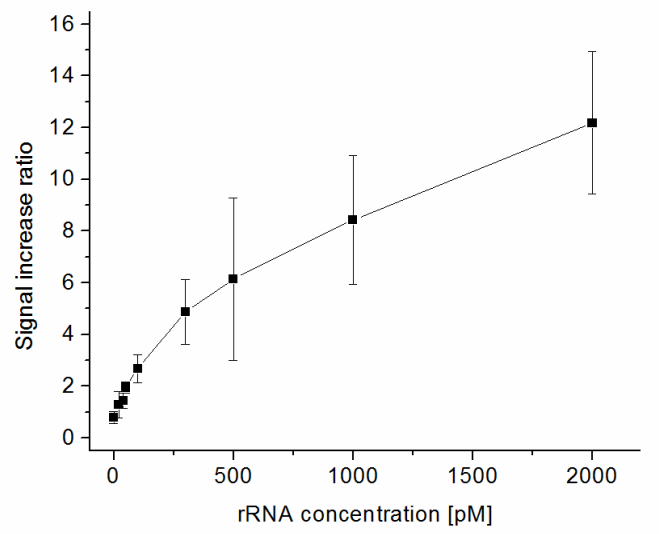

Figure 5 


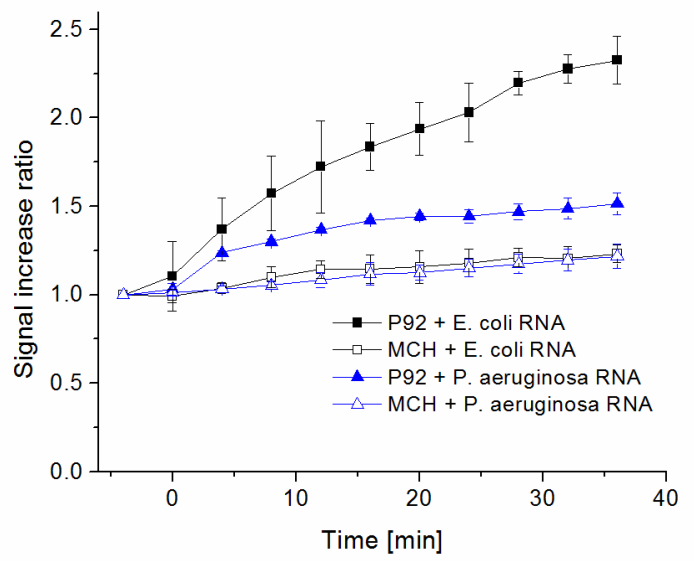

Figure 6 
Supplementary Material
Click here to download S

Click here to download Supplementary Material: Supporting Information_Bachmann et al_R1_BIOS-D-03218.pdf 西

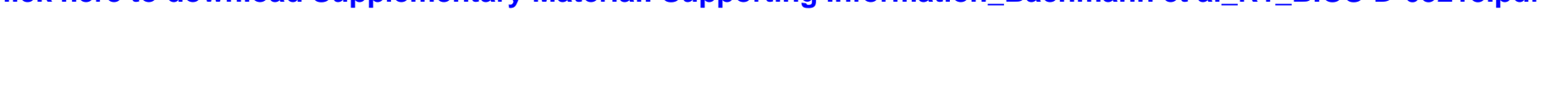
(n) -

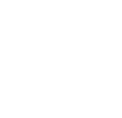
(1) (1) (1) (1) (1) (1)

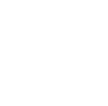

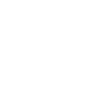
(1)

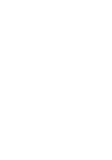
( (1) 
- EIS biosensor for direct detection of E. coli $16 \mathrm{~S}$ rRNA

- No requirement for target amplification, labelling or fragmentation.

- Novel probe design approach combining in silico analysis with fluorescence-based microarray screening and implementation in EIS assay

- Kinetic EIS assay format allowed specific detection of E. coli rRNA within 10 min at ambient temperature 


\section{PROBE SELECTION ENDPOINT ASSAY FORMAT KINETICASSAY FORMAT EIS DETECTION}
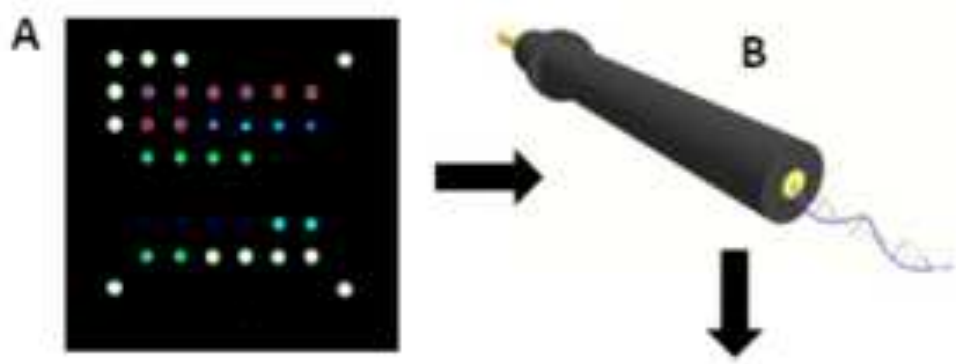

c
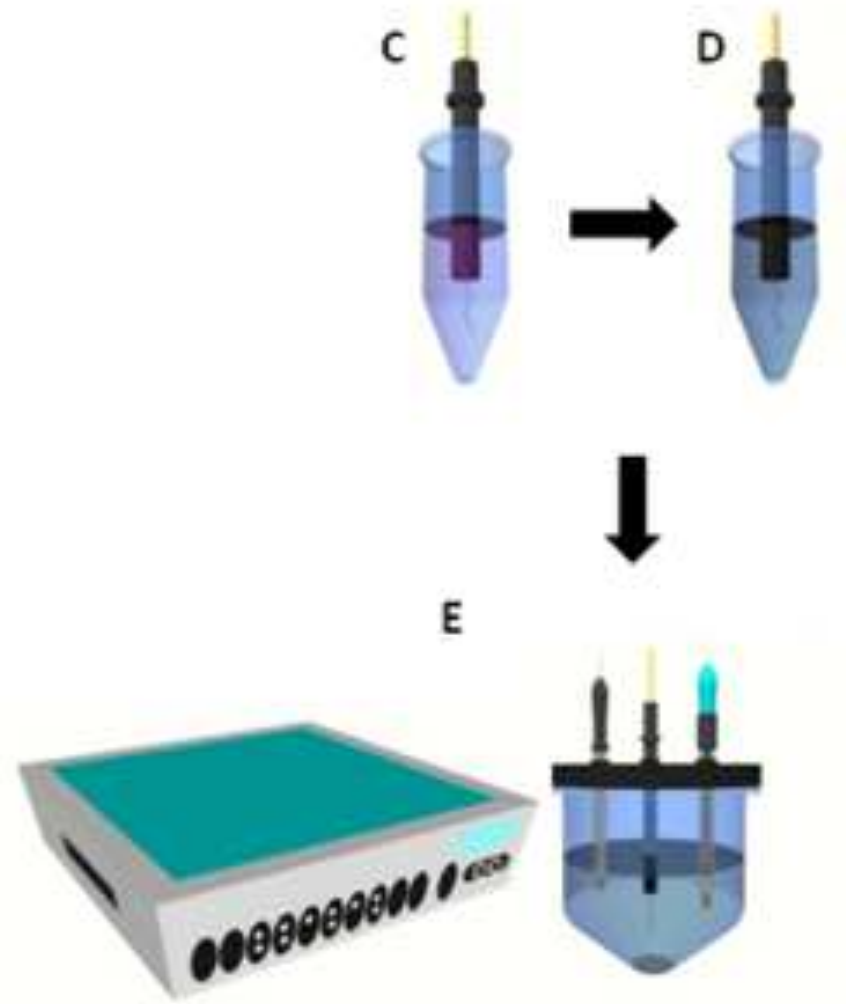

E
$\mathbf{F}$

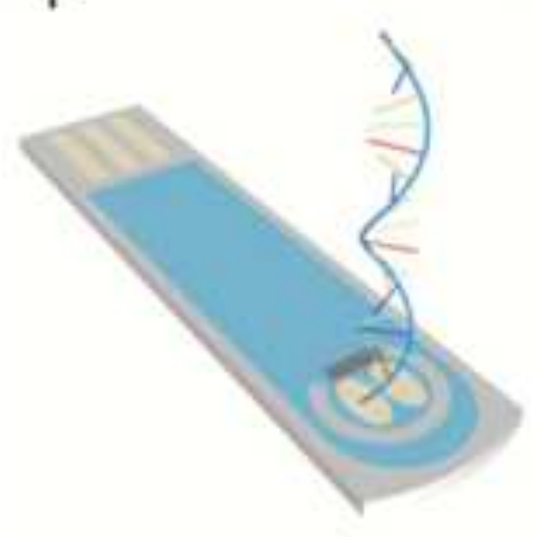

I

G

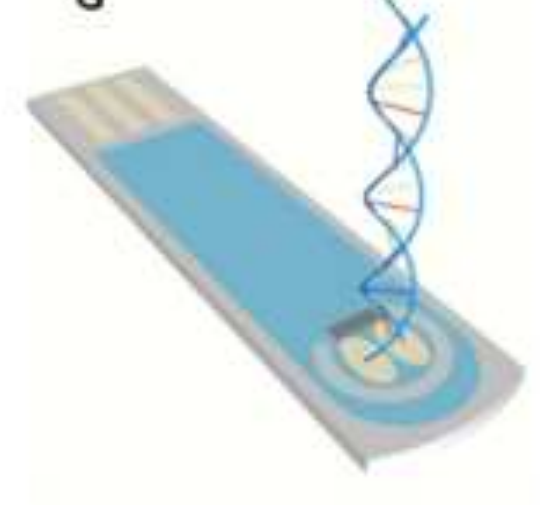

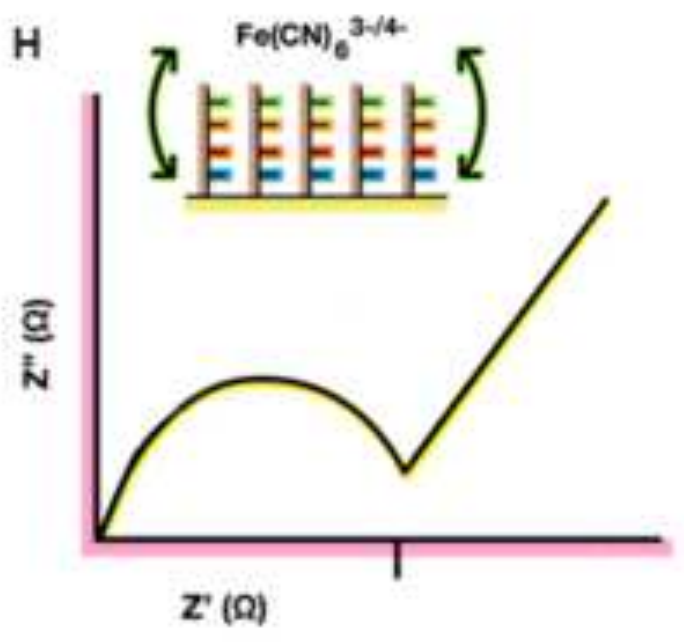

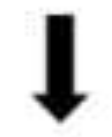

I

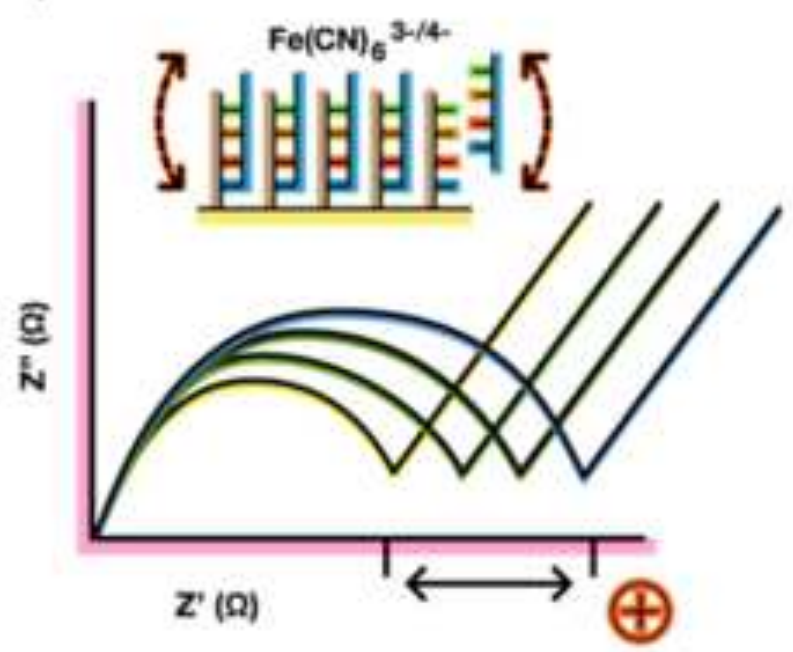




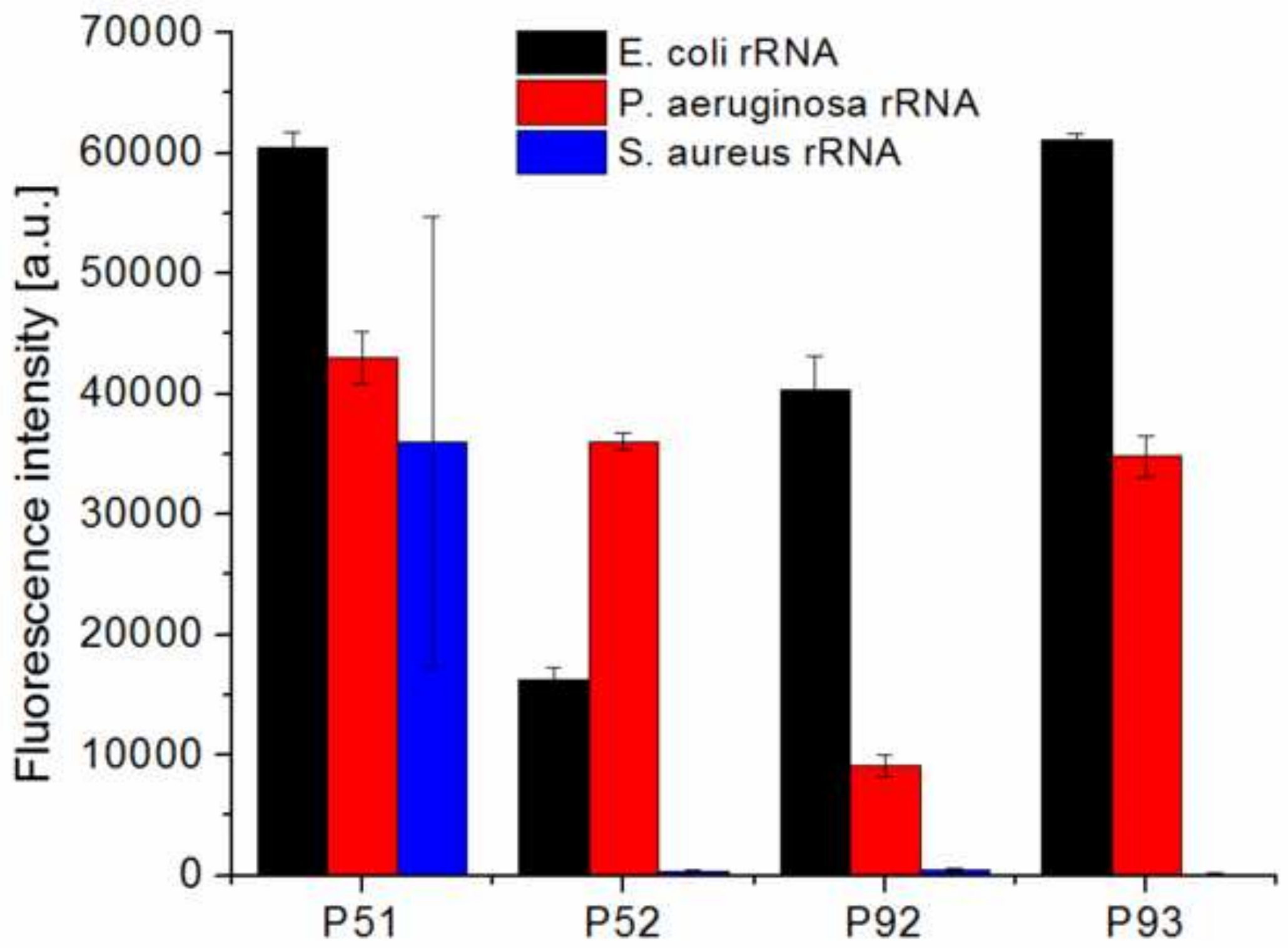




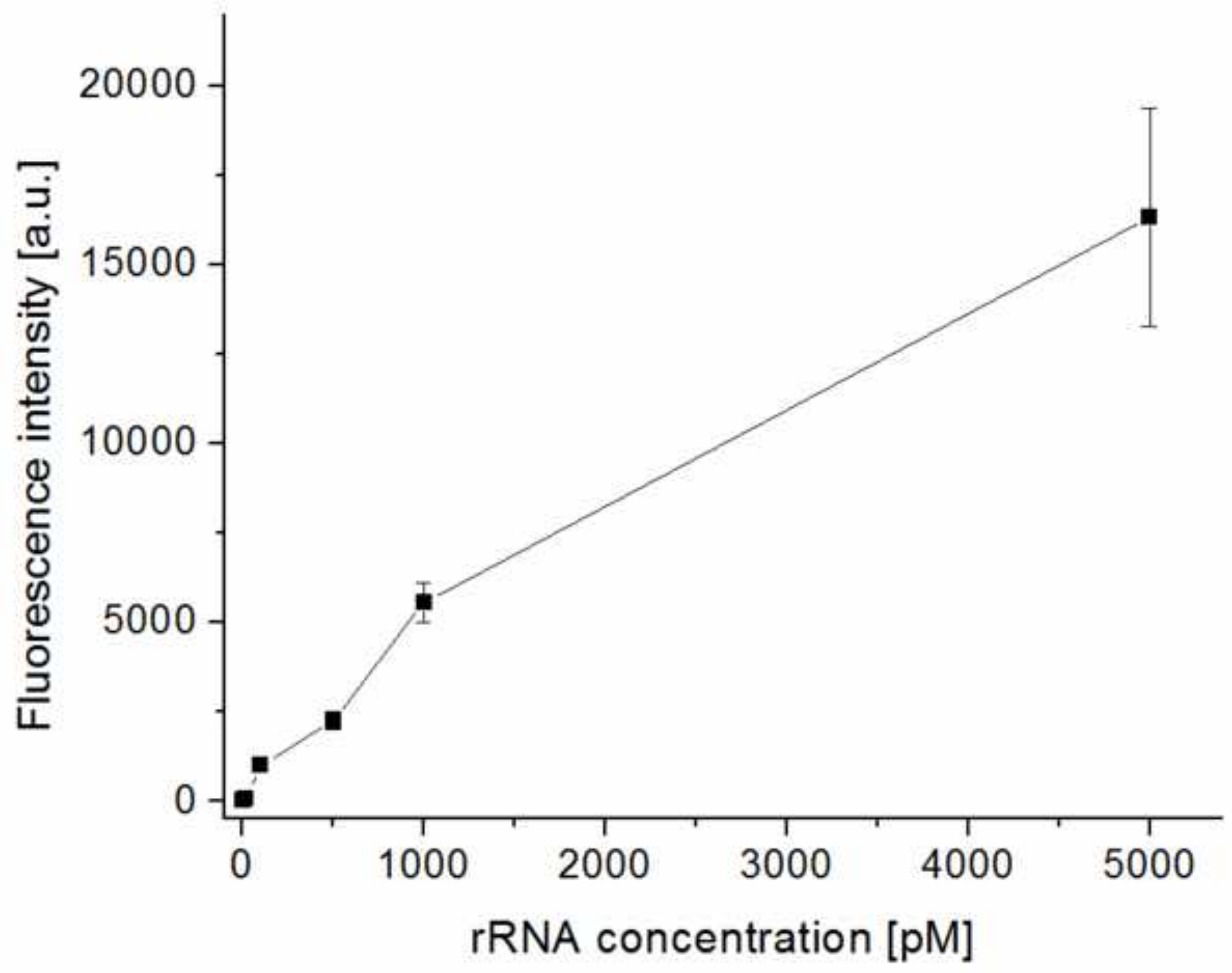




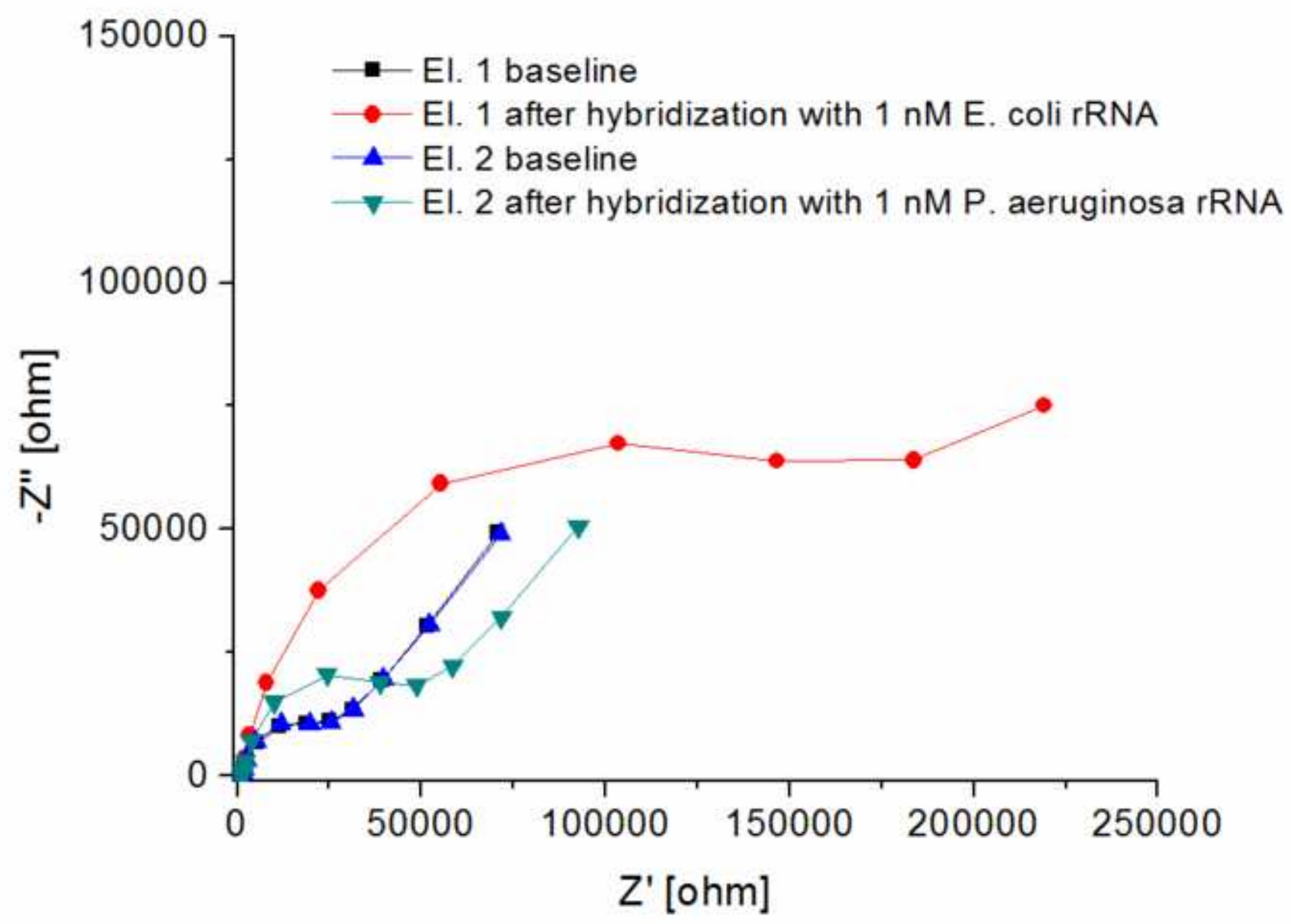




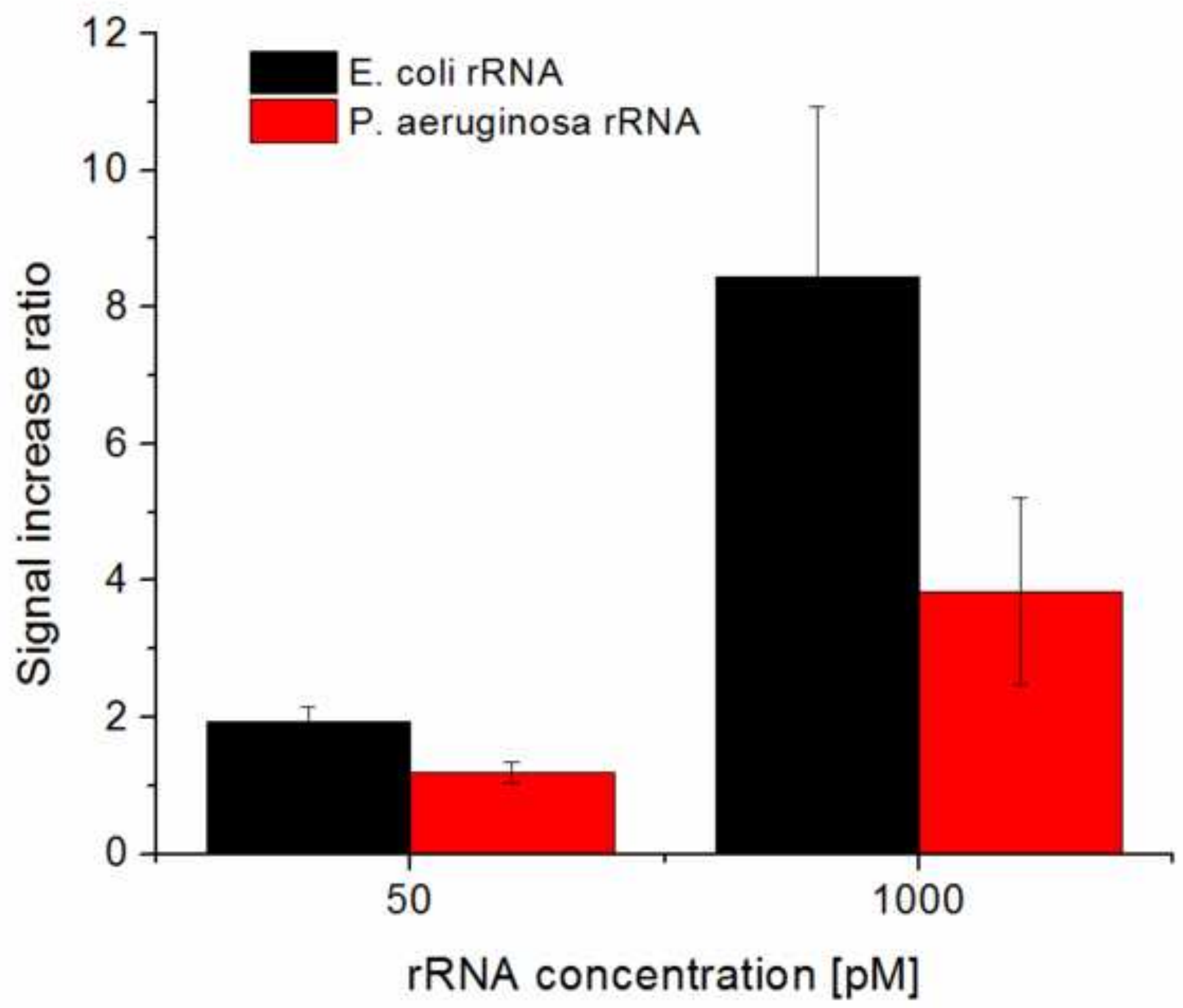




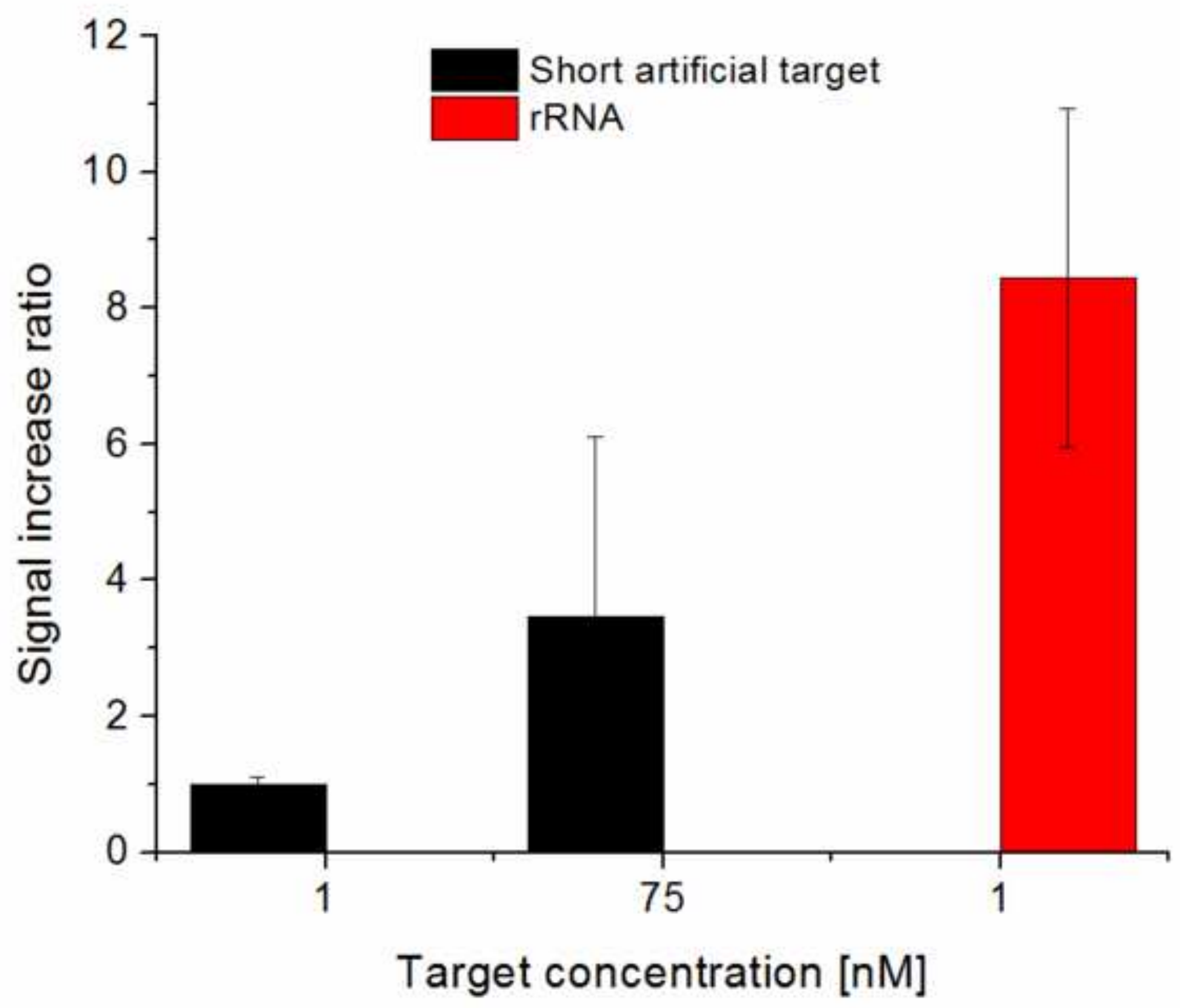




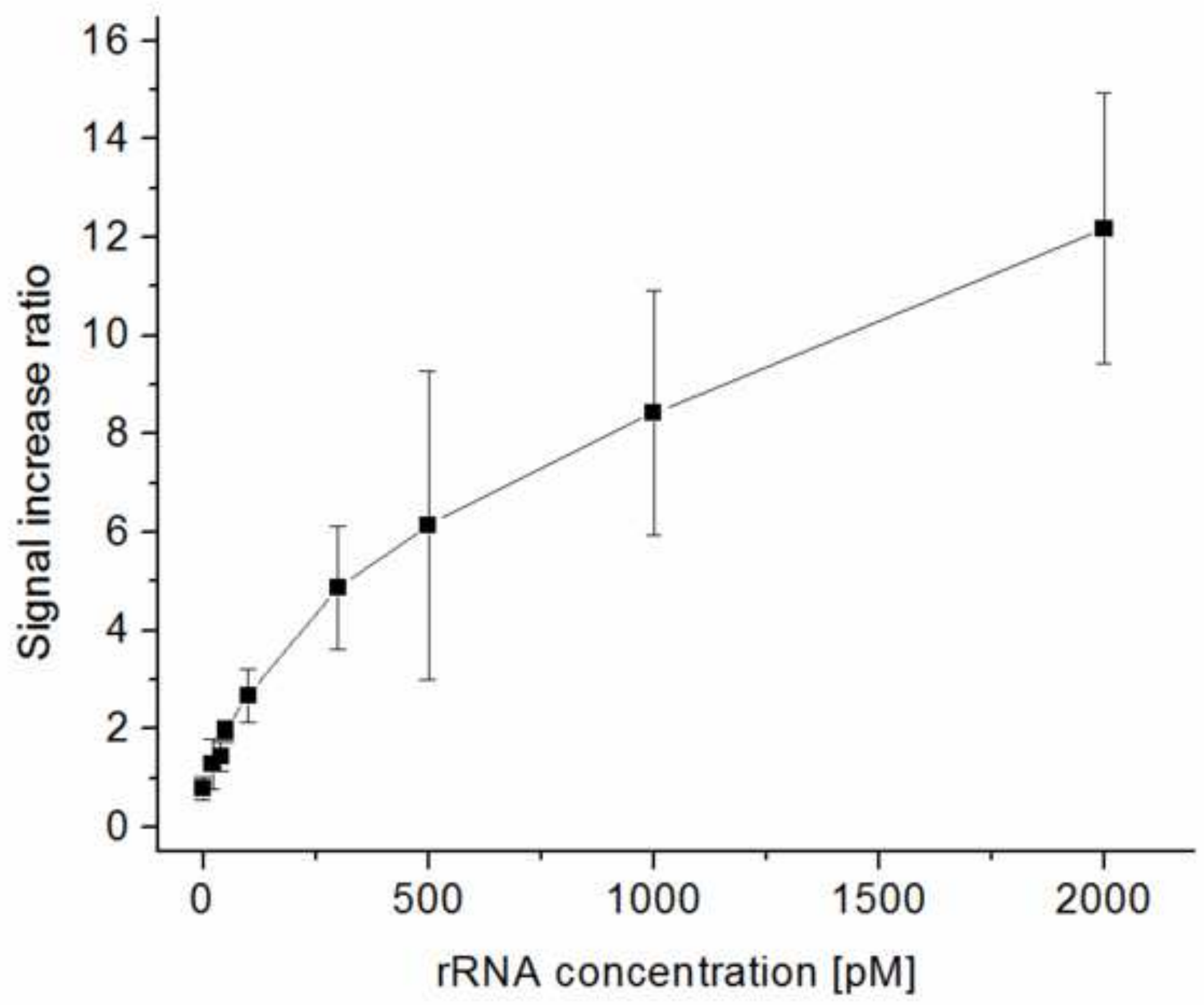




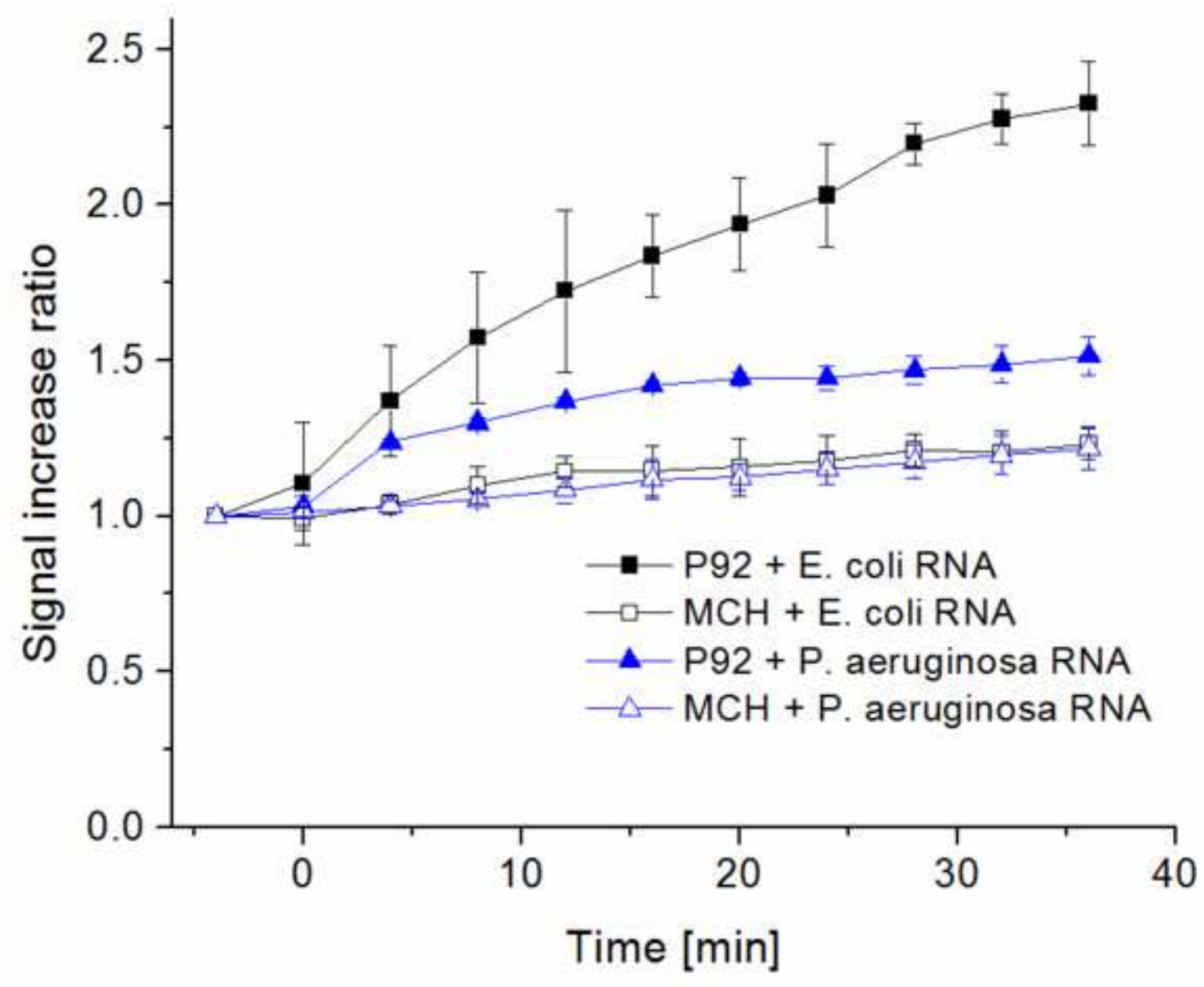

